\title{
Learning through passive participation in asset market bubbles
}

\author{
Timothy N. Cason ${ }^{1} \cdot$ Anya Samek ${ }^{2}$
}

Received: 28 May 2015/Revised: 21 August 2015/Accepted: 26 August 2015/

Published online: 2 September 2015

(C) Economic Science Association 2015

\begin{abstract}
We report a laboratory experiment that investigates the impact of passive participation on bubble formation in asset markets with inexperienced and experienced traders. Some treatments employ pre-market training in which each participant is 'matched' with a trader from a different prior market and observes all trading details but does not directly participate in trading. We find that passive participation, similar to direct experience, significantly reduces mispricing in subsequent markets. This finding suggests that observation of prices is a key mechanism through which experience mitigates bubbles. We also vary whether transaction prices are displayed in a column of text or in a graphical display, and find that among inexperienced and once-experienced traders, markets with the tabular display result in bubbles that are greater in amplitude relative to markets with the graphical display.
\end{abstract}

Keywords Laboratory experiment $\cdot$ Asset mispricing · Finance $\cdot$ Trading experience

JEL Classifications $\quad \mathrm{C} 92 \cdot \mathrm{G} 12 \cdot \mathrm{G} 14$

Electronic supplementary material The online version of this article (doi:10.1007/s40881-015-0013-3) contains supplementary material, which is available to authorized users.

Anya Samek

anyasamek@gmail.com

1 Department of Economics, Purdue University, 403 W. State St., West Lafayette, IN 47906-2056, USA

2 Center for Economic and Social Research, University of Southern California, 635 Downey Way, Los Angeles, CA 90089-3332, USA 


\section{Introduction}

Asset markets throughout history have experienced episodes with prices that increase above fundamental value, followed by a rapid drop. This is often referred to as a 'bubble' and 'crash'. Examples range from the Dutch Tulip craze of the 1600s, to the recent worldwide housing bubble of 2003-2008. Rational expectations models predict that common expectations about the value of the asset should never result in bubbles (Tirole 1982), yet bubbles have formed even with commonlyknown intrinsic values assigned in laboratory experiments (Porter and Smith 2003; Noussair and Tucker 2013; Palan 2013).

A rich literature has investigated behavioral causes of the 'irrational' overbidding that drives up transaction prices in asset markets. Speculation is one rational reason for bubble formation, yet bubbles are still observed in a market where resale (and thus speculation) is not possible (Lei et al. 2001). One of the most robust results in the asset market bubble literature is the effect of experience, defined as previous participation in a similar laboratory asset market, on reducing bubbles (Xia et al. 2012; Haruvy et al. 2007; Dufwenberg et al. 2005; Smith et al. 1988; Van Boening et al. 1993; King et al. 1993). ${ }^{1}$ However, experience in one market does not reliably transfer to another, and bubbles may re-emerge after changes to market parameters (Hussam et al. 2008).

Despite research focused on the role of experience in abating bubbles, the mechanisms through which experience functions are not well understood. This paper investigates whether passive participation, rather than experience (i.e., active participation), is sufficient to reduce asset market bubbles. Passive participants observe the same information as a prior trader, and receive the same payoffs, but do not actively make decisions. Passive participation is similar to observational learning, in which participants observe an active participant but do not otherwise participate. Observational learning has shown to improve decision-making in a variety of economic games (Merlo and Schotter 2003; Kocher et al. 2015). Different from observational learning, our comparisons of passive participation and active participation allow us to carefully isolate the act of making decisions from all other aspects of the environment. Thus, we can explore whether the act of making a decision is integral to the effectiveness of direct and participatory experience at mitigating bubbles.

Specifically, the experiment employs treatments that feature pre-market training in which each participant is 'matched' with a trader from a different prior market and observes all trading details but does not directly participate. Related work has studied overlapping generations of traders, but has not isolated the impact of passive participation (Deck et al. 2014; Xia and Zhang 2012; Alevy and Price 2012). ${ }^{2}$ Huber

\footnotetext{
1 We use the term "bubble" throughout this paper to refer to mispricing generally, as defined by King et al. (1993): "trade in high volume at prices that are considerably at variance from intrinsic value" (page 183).

2 Overlapping generations of traders introduce new injections of cash, which is known to promote bubbles, so that it is not possible to disentangle the role of information alone. Alevy and Price (2012) come closest to disentangling the role of observational learning, but do not directly identify it because of the addition of advice in their design.
} 
et al. (2014) found that experience gained in a laboratory investment game increased pricing efficiency in subsequent asset markets.

One leading explanation of asset market bubbles is trader confusion (Huber and Kirchler 2012; Kirchler et al. 2012). Confusion seems to be reduced when fundamental values are displayed in graphical form (Huber and Kirchler 2012; Baghstanian and Walker 2014), when the asset is framed differently (such as a 'depletable gold mine', Kirchler et al. 2012), or through pre-market training about dividend payments (Lei and Vesely 2009). ${ }^{3}$ To investigate how confusion may interact with passive and active participation, the experiment also varies whether continuously-updated transaction prices are displayed in a column of text or in a visual information display. If confusion about the relationship of prices to asset fundamental values is a reason for bubble formation, increased understanding provided by visual representation may reduce mispricing. While some previous studies have displayed prices graphically (e.g., Deck et al. 2014; Kirchler et al. 2012), none have systematically varied information display to determine its influence on subsequent pricing.

We find that passive participation, similar to experience, significantly reduces mispricing in subsequent markets. This suggests that the observation of transaction prices, or other information available through passive participation such as bids, asks and profits, can substitute for active participation and experience in mitigating bubbles. We also find that among inexperienced and once-experienced traders, markets with a visual representation of trade prices result in bubbles with lower mispricing relative to markets with prices reported in text format.

\section{Experimental design and procedures}

\subsection{Procedures}

The experiment was conducted at the Vernon Smith Experimental Economics Laboratory (Purdue University) using 240 undergraduate student subjects, who were recruited using ORSEE (Greiner 2015) and were allocated across 12 sessions. Ten participants interacted in each market and were able to trade together for the duration of the experiment. We conducted 2 independent market groups (20 subjects) per experimental session. Subjects participated in only one session of this study. Upon arriving to the lab, subjects were seated at computers and the experimenter read the instructions out loud while subjects followed along. (See Appendix I for instructions in ESM.) Earnings were converted to US dollars at the rate of 150 experimental dollars $=\$ 1$. Each session lasted approximately two hours and subjects earned an average of about $\$ 39$ each.

\footnotetext{
3 Related work also explores impact on bubble formation of the pattern of market fundamentals (Noussair and Powell 2010; Stöckl et al. 2010) and the impact of training (Cheung et al. 2014).
} 


\subsection{Trading environment}

We use a version of the Smith et al. (1988) trading environment, and a continuous double auction for traders to buy and sell a finitely lived asset that pays a random dividend to all asset holders at the end of each trading period. In this trading institution (programmed in zTree, Fischbacher 2007), traders could submit a bid or ask and could accept any other trader's bid or ask in continuous time.

Traders participated in three consecutive markets, each consisting of 12, twominute trading periods with a hard close. We conducted three markets to observe behavior of traders both before and after they gained experience. Traders knew how many markets would be conducted in their session. Instructions for each market were distributed immediately before that market opened, and earnings were cumulative.

At the beginning of each market, traders were randomly endowed with one of two portfolio types, with half of the market trading group endowed with 3 shares and 1080 in cash and half endowed with 5 shares and 504 in cash. ${ }^{4}$ At the end of each period, shares paid a publicly announced dividend, randomly determined and uniformly distributed over the values $\{0 e, 8 e, 28 e, 60 e\}$. The one period expected value of each share was $24 e$, so the value of each share at the beginning of the market was $12 \times 24 e=288 e$. Shares were not redeemable for cash at the end of the market and were not transferable across markets. Therefore, these assets had a commonly known and declining (by $24 e$ each period) fundamental value.

\subsection{Treatments}

The experiment included four treatments shown in Table 1. Treatments varied either the display of trade prices or the extent of participation. In markets with a Text display, trade prices were displayed as columns of text. In markets with a Visualized display, trade prices were displayed in a graphical interface, with time on the $\mathrm{X}$-axis and trade price on the $\mathrm{Y}$-axis. In both display formats, average transaction prices were updated and displayed following each trade, and the history of prices for the entire market was available. Appendix II in ESM provides screenshots of each display format. The Text treatment consisted of 3 consecutive Text markets, and the Visualized treatment consisted of 3 consecutive Visualized markets.

To explore the role of passive participation, in the Pre-Text and Pre-Visualized treatments, market 1 was an observation stage only. Each participant in market 1 was "matched" with a participant from a prior market 1 and passively observed prerecorded trades from that market (visualized graphically for Pre-Visualized; and text based for Pre-Text). We matched participants 1:1 such that each participant in the passive participation stage in market 1 was matched with a different anonymous participant with the same portfolio type from the pre-recorded market from a

\footnotetext{
4 The Cash/Asset (CA) ratio in the market is 0.625 , which is below the CA ratios in related work. For instance, Huber and Kirchler (2012) and Dufwenberg et al. (2005) have CA ratios of 1. This may potentially reduce the size of bubbles in our experiment, but the ratio is identical across treatments so it does not impact the treatment comparisons.
} 
Table 1 Summary of treatments

\begin{tabular}{llll}
\hline Treatment & Market 1 & Market 2 & Market 3 \\
\hline 1. Text treatment & Text market & Text market & Text market \\
2. Visualized treatment & Visualized market & Visualized market & Visualized market \\
3. Pre-text treatment & Text market observation & Text market & Text market \\
4. Pre-visualized treatment & Visualized market observation & Visualized market & Visualized market \\
\hline
\end{tabular}

previous session. Thus, although each trader in the passive participation stage had a slightly different experience (observing the specific trades of a different past trader), overall the traders in the passive participation market observed the same public transaction prices unfolding as the participants in the pre-recorded market.

In the passive participation market, each subject was also paid the same amount as his/her "match". Just like the active participants, the passive participants recorded information on record sheets each period, including the dividend per share, number of shares in their account, their dividend payment and their end of period cash balance. Thus, the only difference in market 1 of Pre-Visualized and Pre-Text treatments compared to Visualized and Text treatments is that subjects never made their own bids, asks or trades. The remaining two markets (markets 2 and 3 ) in the Pre-Visualized and Pre-Text treatments were Visualized and Text markets with normal trading (i.e., active participation), respectively.

\subsection{Conjectures}

Comparisons of Market 1 to Markets 2 and 3 allow us to investigate the role of experience. We also compare Market 2 behavior between Pre-Visualized and Visualized treatments and between Pre-Text and Text treatments to investigate the role of passive participation, as compared to direct experience. We conjecture that exposure to a market will promote learning through observation and decrease the amplitude of price bubbles in subsequent markets, similar to previous findings that indicate experience reduces subsequent bubbles. A possible mechanism for the effect of passive participation is feedback in the observed market-either through learning about overall price trends or individual learning strategies. Alternative explanations for the effect of passive participation could be the additional time available to think about the decision (without having to act) or the individual payout (that is linked to one's match).

Comparisons of Text-Market 1 and Visualized-Market 1 allow us to investigate the role of graphical representation on behavior of inexperienced traders. If agents are boundedly rational or do not process price information fully (Simon 1987), then information that is more easily processed will result in less confusion and a reduction in bubbles. Graphical displays may allow users to 'see' patterns in data (Lurie and Mason 2007). Thus, we conjecture that the Visualized market will result in a reduction in bubble formation relative to the Text market. Alternatively, if agents use past prices to form expectations about future prices (Haruvy et al. 2007), 
then an improvement in information processing may cause greater salience of a positive price trend, so the Visualized market could result in an increase in bubble formation relative to the Text market.

\section{Results}

\subsection{Treatment effects}

Figure 1 displays average trading prices by session. Bold black lines represent average prices across all sessions, lighter gradient lines represent average prices by session, and dotted lines represent fundamental value. Deviations from fundamental value are greatest in market 1 relative to markets 2 or 3 . For inexperienced participants in market 1 , deviations are greater in the Text market than in the Visualized market. Prices in the Text treatments show greater variability across sessions compared to prices in the Visualized treatments. ${ }^{5}$

To explore more formally, we conduct statistical tests using the relative absolute deviation (RAD) measure of mispricing and valuation (Stöckl et al. 2010): $(1 / N) \sum_{p=1}^{N}\left|\bar{P}_{t}-F V\right| /|F \bar{V}|$ where $\bar{P}_{t}$ is the volume-weighted mean price in period $t, F V_{t}$ is the fundamental value in period $t, F \bar{V}$ is the average fundamental value of the market and $N$ is the number of periods in the market. RAD, similar to bubble amplitude, measures absolute "mispricing" in the market. Table 2 provides the RAD for each treatment and market. We observe significantly positive RAD across all markets based on Wilcoxon signed-rank tests. This suggests a substantial level of mispricing, as typically seen in previous studies (e.g., Smith et al. 1988).

Our first question concerns the effects of direct experience versus passive participation. As seen in Table 2, experience and passive participation both decrease RAD in the Visualized and Text markets, but the effect appears to be stronger for experience than for passive participation. In the Text market, experience drops average RAD from 0.89 in Market 1 to 0.38 in Market 2, while passive participation results in an average RAD of 0.55 in Market 2. In the Visualized market, experience drops RAD from 0.47 in Market 1 to 0.17 in Market 2, while passive participation results in an RAD of 0.29 in Market 2. Consistent with previous studies showing that experience decreases asset market bubbles (Haruvy et al. 2007; Dufwenberg et al. 2005; Smith et al. 1988; Van Boening et al. 1993), we find that RAD is significantly lower in Market 2 than in Market 1 in both Visualized and in Text treatments (Wilcoxon signed-rank test $p$ value $=0.028$ and 0.046 , respectively, based on independent trading groups as the unit of observation).

Next, we compare the improvement in pricing accuracy for experience and passive participation. The bubble measures in Market 2 of the passive participation treatments indicate that both experience and passive participation significantly decrease amplitude. In the text display markets, the Pre-Text Market 2 RAD is

\footnotetext{
5 Transaction volumes (not shown) are fairly large in all treatments, especially considering the total asset stock is only 40 shares in total. Total trade volume across all periods averages 140, 95 and 98 in markets 1, 2 and 3, respectively, indicating total share turnover between 2.35 and 3.5 on average.
} 


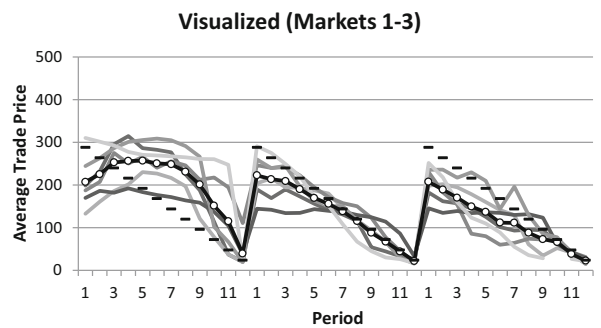

Text (Markets 1-3)
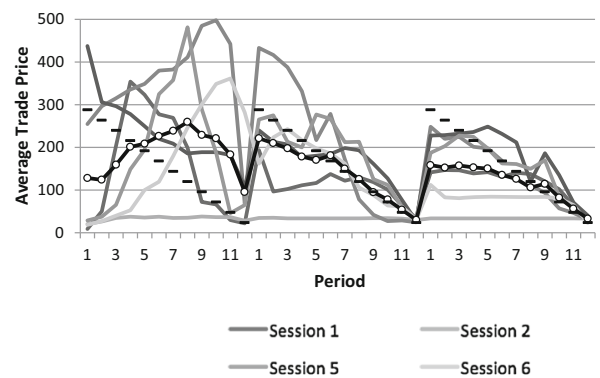

Pre-Visualized (Markets 2-3)

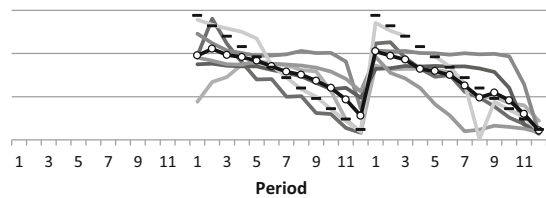

Pre-Text (Markets 2-3)
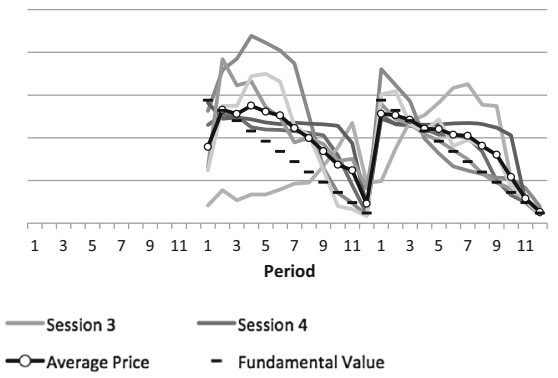

Fig. 1 Average trade prices

significantly lower than Text Market 1 (Wilcoxon signed-rank $p$ value $=0.037$ ). In the Visualized markets, the same effect is significant at the $10 \%$ level for RAD ( $p$ value $=0.078)$. However, RAD in Pre-Text Market 2 is not significantly different from Text Market 2 (Mann-Whitney $p$ value $>0.10$ ) and RAD in Pre-Vis Market 2 is not significantly different from Visualized Market 2 ( $p$ value $>0.10$ ). This suggests that passive participation may be a sufficient proxy for direct experience, though we cannot definitively conclude this due to small sample sizes and limited power.

Result 1: Passive participation reduces subsequent bubble mispricing in the market, similar to bubble reductions due to active participation (i.e., direct experience).

Finally, we explore the effect of visual or tabular display of prices for inexperienced participants. In Market 1, average RAD in the Visualized treatment is 0.47 while RAD in the Text Market 1 is 0.89 . RAD is lower among inexperienced traders in the Visualized market compared to the Text market (Mann-Whitney $p$ value $=0.023) .{ }^{6}$ The larger average $\mathrm{RAD}$ observed in the Text treatment is also significantly greater than the Visual treatment in Market 2 among once-experienced traders $(p$ value $=0.037)$.

\footnotetext{
${ }^{6}$ Notice the large negative bubble in market 1 of session 2 in the Text treatment. Even when removing this outlier observation our results that RAD is significantly lower in Visualized versus Text continue to hold (Mann-Whitney $p$ value $=0.045$ ). Because the severe mispricing of this negative bubble "cancels out" some of the more common positive mispricing, no significant differences exist between the visual and text display for Stöckl et al. (2010) other measure that reflects average (signed) price errors in the market, relative deviation $(\mathrm{RD})$.
} 
Table 2 Relative absolute deviation (RAD) by Treatment and Market Number

\begin{tabular}{|c|c|c|c|}
\hline & \multicolumn{3}{|c|}{ Relative absolute deviation (RAD) } \\
\hline & Market 1 & Market 2 & Market 3 \\
\hline 1. Text treatment & $\begin{array}{c}0.89(0.31) \\
N=6\end{array}$ & $0.38(0.22) N=6$ & $0.37(0.25) N=6$ \\
\hline 2. Visualized treatment & $\begin{array}{c}0.47(0.13) \\
N=6\end{array}$ & $0.17(0.10) N=6$ & $0.30(0.10) N=6$ \\
\hline 3. Pre-text treatment & & $0.55(0.18) N=6$ & $0.25(0.19) N=6$ \\
\hline 4. Pre-visualized treatment & & $0.29(0.13) N=6$ & $0.29(0.14) N=6$ \\
\hline $\begin{array}{l}\text { Statistical analysis (Wilcoxon } \\
\text { and Mann-Whitney non- } \\
\text { parametric tests) }\end{array}$ & $\begin{array}{l}\text { Text different } \\
\quad \text { from } \\
\text { visualized: } \\
p \text { value }=0.023\end{array}$ & $\begin{array}{l}\text { Text different from } \\
\text { visualized: } \\
p \text { value }=0.037 \\
\text { Pre-text different from } \\
\text { Market } 1 \text { Text: } \\
p \text { value }=0.037 \\
\text { Pre-Visualized different } \\
\text { from Market } 1 \\
\text { Visualized: } \\
p \text { value }=0.078 \\
\text { Text not significantly } \\
\text { different from Pre-Text } \\
\text { in Market } 2: \\
p \text { value }>0.10 \\
\text { Visualized not } \\
\text { significantly different } \\
\text { from Pre-Visualized: } \\
p \text { value }>0.10\end{array}$ & $\begin{array}{l}\text { No statistical } \\
\text { differences between } \\
\text { any treatments in } \\
\text { Market } 3\end{array}$ \\
\hline
\end{tabular}

Standard Deviations in Parentheses. $P$ values reflect results of non-parametric Wilcoxon and MannWhitney tests comparing the treatments to one another

Result 2: Among inexperienced and once-experienced traders, visualizing prices in a graph significantly decreases RAD compared to displaying prices in text.

We obtain similar results using an alternate measure of absolute mispricing usually called amplitude (Hussam et al. 2008); see Appendix III in ESM. No significant differences exist for asset market bubble duration or turnover.

\subsection{What mechanisms drive the effect of passive participation?}

A novel feature of this experiment is the random assignment of traders in the passive participation treatments to different experiences, uncorrelated with their own decisions. This allows us to measure the effect of exogenous observed trading histories and price trends on subsequent decision-making. Here we look at individual strategies and session-based learning. We first classify individual strategies based on traders' propensity to make "safe" trades (buy at prices no higher than or sell at prices no lower than fundamental value) versus "risky" trades 
(buy above or sell below fundamental value). Traders who make more safe trades earn more in the market overall. ${ }^{7}$

The adoption of safe and risky trading strategies by individual traders is correlated across markets, suggesting that the strategies employed are relatively stable as traders gain experience. The correlation in traders' net number of safe rather than risky trades ranges between 0.40 and 0.76 when considered across any two adjacent markets in each treatment. This correlation is always significant, except in the Text treatment (two-tailed $p$ values are less than 0.03 in the other treatments, assessed using linear regressions with robust errors with session clustering). ${ }^{8}$

The first market in the Pre-Text and Pre-Visualized treatments allowed passive participants to see the individual trading activity of their match, and observe their match making safe or risky trades given transaction prices relative to fundamental value, as well as the profitability of their match's strategy. We might expect that observing the profitable (safe trading) strategy would increase the probability that the passive trader would adopt this strategy in the following market. However, the correlation between the number of safe relative to risky trades in Markets 2 and 3 for the Pre-Text and Pre-Visualized treatments and the safe relative to risky trades by the matched trader observed in Market 1 is weak. In particular, the correlation of net safe trades made by a trader in Market 2 with the matched active trader in Market 1 is 0.054 for the Pre-Text treatment, 0.094 for the Pre-Visualized treatment, and 0.074 for these treatments pooled. These correlations never approach statistical significance ( $p$ values $0.57,0.43$ and 0.67 , respectively). Similarly, the number of net safe trades made in Market 2 of the Pre-Text and Pre-Visualized treatments is only slightly closer to the matched active trader in Market 1 (average deviation of 6.3 trades) than to the nine other active traders in Market 1 (average deviation of 6.6 trades).

Thus, the smaller mispricing and bubble sizes that arise through passive participation in the aggregate (Result 1) do not apparently occur through adoption of observed trading strategies such as the number of safe and risky trades executed. We obtain similar results for other trading strategies, such as the number of net shares acquired (number of shares purchased less shares sold) during different sets of early periods, or the timing of when traders switch to safe trading strategies. ${ }^{9}$

As noted above, individuals' use of safe or risky trading strategies is significantly correlated across markets. Similarly, individuals' earnings are also correlated across markets, but at weaker levels (correlation coefficients of $0.18-0.49$ ) that are not always statistically significant. However, the Market 2 or 3 earnings of passive

\footnotetext{
7 Pooled across all markets and treatments, traders who made more safe than risky trades realized 52 percent greater market profits compared to traders who made more risky than safe trades. For each additional "net" safe rather than risky trade, market earnings were higher on average by 80 experimental dollars.

${ }^{8}$ The correlations reported here are the simple Pearson product-moment correlation coefficients (Stata command correlate).

9 For this latter strategy focusing on timing, we calculated the final period that each trader executed an "unsafe" trade (i.e., buy above or sell below fundamental value) in each market. The correlation of this switch to a safe trading strategy by a trader in Market 2 with the matched active trader in Market 1 is only $0.132(p$ value $=0.28)$ for the Pre-Text treatment and $0.178(p$ value $=0.37)$ for the Pre-Visualized treatment.
} 
Text (Market 1)

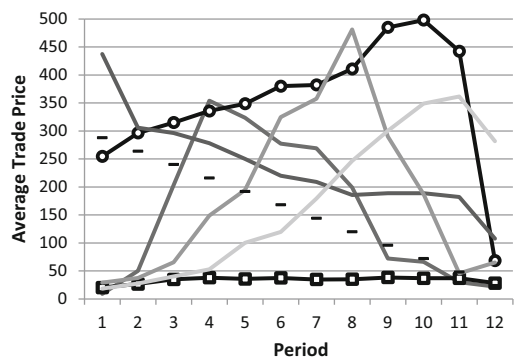

- Session 1

- Session 5

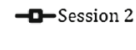

- Session 6
Pre-Text (Markets 2-3)
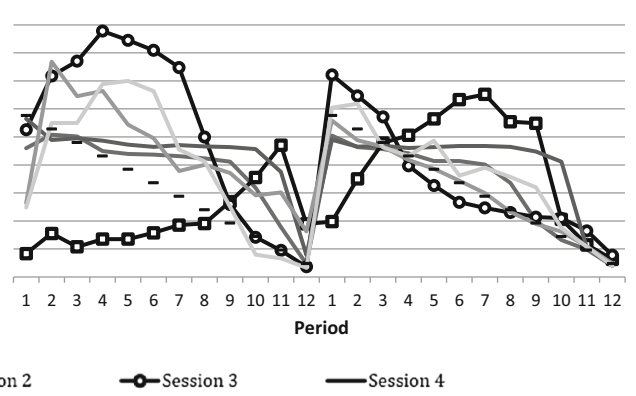

- Fundamental Value

Fig. 2 Mean prices for text (Market 1) and paired pre-text sessions (Markets 2 and 3)

participants in the Pre-Text and Pre-Visualized treatments are never significantly correlated with the Market 1 earnings received by their matched trader.

Although we do not find evidence that traders adopt the individual trading strategies that they observe, or earn profits correlated with their matched trader, passive participants may reach different conclusions about the market price trends based on those observed in their matched markets. Since we match each session with a different previous market session, traders observe exogenous and substantially different overall price trends across the different sessions. The data provide some evidence to suggest that observation of particular price trends result in similar price patterns in the following market. We focus on the strongest examples of mispricing. In one session of the Text treatment we observe an instance in which a negative bubble forms and remains for the entire session. In another session of the Text treatment, we observe an instance of a large positive bubble that persists throughout most periods of the first market.

Figure 2 displays the prices observed across the three markets for the Pre-Text treatment, highlighting the sessions with the negative (Session 2) and strongly positive (Session 3) bubbles. During Market 2, Session 2 (highlighted with squares) experiences a negative bubble similar to that observed for the replay in Market 1; while Session 3 (highlighted with circles) experiences the large positive bubble in Market 2 similar to that observed for the replay in Market 1. By Market 3, both sessions exhibit more typical price trends, suggesting that the observed price trend is learned, but that a single market of own experience mitigates the effect. Similar instances of high mispricing are not observed in the Visual treatments, so this conclusion is restricted to Text treatments.

\section{Conclusion}

Our main finding is that passive participation significantly reduces bubble formation, similar to direct experience (i.e., active participation). While related work has found that experience mitigates bubbles, the mechanisms are unclear. Our 
results point to observation as a key mechanism, helping advance the literature beyond the simple conclusion that 'experience matters.' Recent work has also found positive effects for simulation based learning elsewhere, notably in financial investing (e.g., Kaufmann et al. 2013; Bradbury et al. 2014).

Our second finding is that visual presentation of prices reduces mispricing for inexperienced and once-experienced traders. This suggests that visual representation of the price trend may improve understanding of the market and is consistent with related work that seeks to improve cognition through visual displays (Savikhin et al. 2011).

The finding that passive participation reduces bubbles in a subsequent market deserves additional investigation. Our evidence suggests that the observation of a market price trend, rather than the observation of the trading strategy and dividend flow of the 'match,' may have a greater influence on future behavior. Future work should explore experimentally varying feedback, the time that traders have to observe market outcomes and payment at the passive participation stage to further learn the mechanisms for learning through passive participation.

Our work on exploring observational learning also has practical applications. For instance, 'job shadowing' programs are a popular type of on-the-job training for new employees in practice. ${ }^{10}$ Our results may support the use of such programs for employees in trading firms, though more research is needed to explore their effect.

Acknowledgments This material is based upon work supported by the National Science Foundation under Grant Number 09064963. For helpful comments we thank the editors and two anonymous referees, Jonathan Alevy, Cary Deck, Jürgen Huber, Michael Kirchler, Thomas Stöckl, Steven Tucker, Kevin McCabe, and audiences at the University of Melbourne, the University of California-San Diego, George Mason University and the Economic Science Association Meetings. We thank Justin Krieg for excellent research assistance. Any remaining errors are ours.

\section{References}

Alevy, J. E., \& Price, M. K. (2012). Advice and fictive learning: the pricing of assets in the laboratory. Working Paper No. 2012-07. University of Alaska Anchorage.

Baghestanian, S., \& Walker TB. (2014). Thar she blows again: reducing anchoring rekindles bubbles. Working Paper.

Bradbury, M. A. S., Hens, T., \& Zeisberger, S. (2014). Improving investment decisions with simulated experience. Review of Finance, forthcoming, doi:10.1093/rof/rfu021.

Cheung, S., Hedegaard, M., \& Palan, S. (2014). To see is to believe: common expectations in experimental asset markets. European Economic Review, 66, 84-96.

Deck, C., Porter, D., \& Smith, V. (2014). Double bubbles in assets markets with multiple generation. Journal of Behavioral Finance, 15, 79-88.

Dufwenberg, M., Lindqvist, T., \& Moore, E. (2005). Bubbles and experience: An experiment. American Economic Review, 95, 1731-1737.

\footnotetext{
${ }^{10}$ For websites addressing the importance of job shadowing in practice, see: http://humanresources. about.com/od/training/g/job-shadowing.htm and https://www.linkedin.com/pulse/2014082608214928092492-essay-training-through-job-shadowing-a-result-based-approach.
} 
Fischbacher, U. (2007). z-Tree: Zurich toolbox for ready-made economic experiments. Experimental Economics, 10, 171-178.

Greiner, B. (2015). Subject pool recruitment procedures organizing experiments with ORSEE. Journal of the Economic Science Association, 1(1), 114-125.

Haruvy, E., Lahav, Y., \& Noussair, C. N. (2007). Traders' expectations in asset markets: experimental evidence. The American Economic Review, 97, 1901-1920.

Huber, J., \& Kirchler, M. (2012). The impact of instructions and procedure on reducing confusion and bubbles in experimental asset markets. Experimental Economics, 15, 89-105.

Huber, J., Kirchler, M. \& Stöckl, T. (2014). The influence of investment experience on market prices. Laboratory evidence. Working Paper.

Hussam, R. N., Porter, D., \& Smith, V. L. (2008). Thar she blows: Can bubbles be rekindled with experienced subjects? The American Economic Review, 98, 924-937.

Kaufmann, C., Weber, M., \& Haisley, E. (2013). The role of experience sampling and graphical displays on one's investment risk appetite. Management Science, 59, 323-340.

King, R., Smith, V., Williams, A., \& van Boening, M. (1993). The robustness of bubbles and crashes in experimental stock markets. In R. Day \& P. Chen (Eds.), Nonlinear Dynamics and Evolutionary Economics (pp. 183-200). Oxford: Oxford University Press.

Kirchler, M., Huber, J., \& Stöckl, T. (2012). Thar she bursts: Reducing confusion reduces bubbles. The American Economic Review, 102, 865-883.

Kocher, M. G., Sutter, M., \& Wakolbinger, F. (2015). The impact of naïve advice and observational learning in beauty-contest games. Journal of Labor Economics, 33(2), 269-296.

Lei, V., Noussair, C. N., \& Plott, C. R. (2001). Nonspeculative bubbles in experimental asset markets: Lack of common knowledge of rationality vs. actual irrationality. Econometrica, 69, 831-859.

Lei, V., \& Vesely, F. (2009). Market efficiency: Evidence from a no-bubble asset market experiment. Pacific Economic Review, 14, 246-258.

Lurie, N. H., \& Mason, C. H. (2007). Visual representation: Implications for decision making. Journal of Marketing, 71, 160-177.

Merlo, A., \& Schotter, A. (2003). Learning by not doing: an experimental investigation of observational learning. Games and Economic Behavior, 42, 116-136.

Noussair, C. N., \& Powell, O. (2010). Peaks and valleys: Price discovery in experimental asset markets with non-monotonic fundamentals. Journal of Economic Studies, 37, 152-180.

Noussair, C. N., \& Tucker, S. (2013). Experimental research on asset pricing. Journal of Economic Surveys, 27, 554-569.

Palan, S. (2013). A review of bubbles and crashes in experimental asset markets. Journal of Economic Surveys, 27, 570-588.

Porter, D. P., \& Smith, V. L. (2003). Stock market bubbles in the laboratory. The Journal of Behavioral Finance, 4, 7-20.

Savikhin, A., Lam, HC., Brian F., \& Ebert, DS. 2011. An experimental study of financial portfolio selection with visual analytics for decision support. In 44th Hawaii International Conference on System Sciences (HICSS), IEEE, pp. 1-10.

Simon, H. A. (1987). Bounded rationality. In John Eatwell, Murray Milgate, \& Peter Newman (Eds.), The New Palgrave: A Dictionary of Economics (pp. 15-18). New York: Palgrave Macmillan.

Smith, V. L., Suchanek, G. L., \& Williams, A. W. (1988). Bubbles, crashes, and endogenous expectations in experimental spot asset markets. Econometrica, 56, 1119-1151.

Stöckl, T., Huber, J., \& Kirchler, M. (2010). Bubble measures in experimental asset markets. Experimental Economics, 13, 284-298.

Tirole, J. (1982). On the possibility of speculation under rational expectations. Econometrica, 50, 1163-1181.

Van Boening, M. V., Williams, A. W., \& LaMaster, S. (1993). Price bubbles and crashes in experimental call markets. Economics Letters, 41, 179-185.

Xia, H., \& Zhang, J. (2012). Bubbles and experience: an experiment with a steady inflow of new traders. Working Paper, Center for Interuniversity Research and Analysis on Organizations, Montreal, Canada. 